\title{
PROLONGED HEMODYNAMIC STABILITY DURING ARTERIOVENOUS CARBON DIOXIDE REMOVAL FOR SEVERE RESPIRATORY FAILURE
}

Robert L. Brunston, Jr., MD ${ }^{\mathrm{a}}$

Weike Tao, MD ${ }^{\mathrm{a}}$

Akhil Bidani, $\mathrm{MD}, \mathrm{PhD}^{\mathrm{b}}$

Scott K. Alpard, $\mathrm{MD}^{\mathrm{a}}$

Daniel L. Traber, $\mathrm{PhD}^{\mathrm{c}}$

Joseph B. Zwischenberger, MD ${ }^{\mathrm{a}, \mathrm{b}}$
Objective: The effects of prolonged arteriovenous carbon dioxide removal on hemodynamics during severe respiratory failure were evaluated in adult sheep with severe smoke inhalation injury. Methods: Adult female sheep ( $n=6,33.8 \pm 5.2 \mathrm{~kg}$ ) were subjected to intratracheal cotton severe smoke insufflation to a mean carboxyhemoglobin level of $83 \% \pm 3 \%$. Twenty-four hours after injury, a low-resistance $2.5 \mathrm{~m}^{2}$ membrane oxygenator was placed in a carotid-to-jugular pumpless arteriovenous shunt at unrestricted flow to allow complete carbon dioxide removal and reductions in ventilator support. Animals remained conscious, and heart rate, cardiac output, mean arterial pressure, and pulmonary arterial pressure were measured at baseline, after injury, and daily during support with the arteriovenous carbon dioxide removal circuit for 7 days. Results: All animals survived the study period. Carbon dioxide removal ranged from $99.7 \pm 13.7$ to $152.2 \pm 16.2 \mathrm{ml} / \mathrm{min}$, and five $(83 \%)$ of the six animals were successfully weaned from the ventilator before day 7 . During full support with the arteriovenous carbon dioxide removal circuit, shunt flow ranged from $1.24 \pm 0.06$ to $1.43 \pm 0.08 \mathrm{~L} / \mathrm{min}$ and accounted for $20.1 \% \pm 1.4 \%$ to $25.9 \%$ $\pm 2.4 \%$ of cardiac output. No statistically significant changes in heart rate, cardiac output, mean arterial pressure, or pulmonary artery pressure were demonstrated over the study course despite the extracorporeal shunt flow. Conclusions: Arteriovenous carbon dioxide removal as a simplified means of extracorporeal gas exchange support is relatively safe without adverse hemodynamic effects or complications. (J Thorac Cardiovasc Surg 1997; 114:1107-14)
$D^{\mathrm{c}}$ espite advances in critical care, the adult respiratory distress syndrome (ARDS) still carries approximately a 50\% mortality rate. ${ }^{1,2}$ Current therapy is supportive as clinicians apply mechanical ventilation to assist oxygenation and promote carbon dioxide $\left(\mathrm{CO}_{2}\right)$ excretion. Mechanical ventilation

From the Departments of Surgery, ${ }^{\mathrm{a}}$ Medicine, ${ }^{\mathrm{b}}$ and Anesthesiology, ${ }^{c}$ University of Texas Medical Branch and Shriners Burns Institute, Galveston, Tex.

Supported by Shriners Hospitals for Crippled Children (grant 8530).

Presented at the Twenty-ninth Annual Meeting of the American Burn Association, New York, N.Y., March 19-22, 1997.

Received for publication May 15, 1997; revisions requested June 30, 1997; revisions received July 31, 1997; accepted for publication July 31, 1997.

Address for reprints: Joseph B. Zwischenberger, MD, Division of Cardiothoracic Surgery, 301 University Blvd., University of Texas Medical Branch, Galveston, TX 77550-0528.

Copyright (C) 1997 by Mosby-Year Book, Inc.

$0022-5223 / 97 \$ 5.00+0 \quad \mathbf{1 2} / \mathbf{1} / \mathbf{8 5 2 7 4}$ has well-recognized sequelae to both the injured and noninjured portions of the lung during the obligatory gas exchange. Sustained high airway pressures, with the use of either pressure- or volumecontrolled modes of ventilation, lead to pressureassociated permeability edema ${ }^{3}$ and histopathologic changes nearly indistinguishable from those seen in ARDS. ${ }^{4}$ Recent work suggests alveolar overdistention is mainly responsible for the damage. ${ }^{5}$ To reduce the high pressures and associated barotrau$\mathrm{ma} /$ volutrauma, recent ventilator management strategies limit inflation pressures at the expense of an increase in systemic $\mathrm{CO}_{2}$ levels. This technique, termed permissive hypercapnia, has recently been shown to reduce the incidence of barotrauma/volutrauma and improve survival in ARDS. ${ }^{6}$

The success of venoarterial extracorporeal membrane oxygenation, ${ }^{7}$ especially in the neonatal population, has led to a resurgence in the use of extracorporeal techniques in the treatment of ARDS in the pediatric and adult populations. The 
concept of venovenous extracorporeal $\mathrm{CO}_{2}$ removal to allow a reduction in ventilatory support and associated barotrauma/volutrauma was applied by Gattinoni and associates ${ }^{8,9}$ to provide total $\mathrm{CO}_{2}$ extraction and satisfy systemic oxygenation requirements using apneic oxygenation. ${ }^{10}$ Both extracorporeal $\mathrm{CO}_{2}$ removal and extracorporeal membrane oxygenation involve the use of an extracorporeal circuit and the attendant potential for related complications. ${ }^{11}$ The intravenacaval oxygenator was developed by Mortensen ${ }^{12}$ to eliminate the need for extracorporeal blood circulation and still provide gas exchange. However, the intravenacaval oxygenator was limited by surface area and could only remove approximately $30 \%$ of the metabolic $\mathrm{CO}_{2}$ production.

To simplify the extracorporeal component and yet achieve adequate $\mathrm{CO}_{2}$ removal, Barthelemy and colleagues $^{13}$ combined a pumpless artery-to-vein shunt with a membrane oxygenator and the ventilator management technique of apneic oxygenation to satisfy all the gas exchange needs of a large animal for up to 24 hours. Subsequently Awad and colleagues ${ }^{14}$ demonstrated the feasibility of prolonged extracorporeal $\mathrm{CO}_{2}$ removal (7 days) with the use of oxygenators designed for cardiopulmonary bypass interposed in an arteriovenous shunt in a healthy animal model without complications. Unfortunately, these studies were compromised by high circuit resistance $(>30 \mathrm{~mm} \mathrm{Hg}$ ) to spontaneous arteriovenous blood flow, necessitating a mean arterial pressure greater than $110 \mathrm{~mm} \mathrm{Hg}$ to achieve adequate flow for total $\mathrm{CO}_{2}$ removal. Other arteriovenous $\mathrm{CO}_{2}$ removal $\left(\mathrm{AVCO}_{2} \mathrm{R}\right)$ studies have also been accompanied by hemodynamic instability. ${ }^{15}$

We recently developed an $\mathrm{AVCO}_{2} \mathrm{R}$ circuit with use of a new low-resistance membrane oxygenator to provide total $\mathrm{CO}_{2}$ removal in both healthy ${ }^{16}$ and injured ${ }^{17}$ sheep models of severe respiratory failure. Total $\mathrm{CO}_{2}$ removal could be achieved with significant reductions in minute ventilation and peak inspiratory pressures. In these studies, $\mathrm{AVCO}_{2} \mathrm{R}$ circuit flow was up to 1.4 to $1.6 \mathrm{~L} / \mathrm{min}$, representing approximately $20 \%$ to $29 \%$ of the animals' spontaneous cardiac output with a circuit resistance less than $10 \mathrm{~mm} \mathrm{Hg}$. Although an arteriovenous shunt up to $29 \%$ cardiac output allowed a reduction in mechanical ventilatory support to approximately $16 \%$ of the baseline requirements, the long-term impact on hemodynamic function during ARDS remains unknown. In the present study, we subjected adult sheep to a severe smoke inhalation injury to induce ARDS, then applied $\mathrm{AVCO}_{2} \mathrm{R}$ at sufficient shunt flow for total $\mathrm{CO}_{2}$ removal to evaluate the effect of sustained $\mathrm{AVCO}_{2} \mathrm{R}$ flow on critical hemodynamic variables over 7 days. This investigation was necessary before our anticipated adult and pediatric clinical $\mathrm{AVCO}_{2} \mathrm{R}$ trials for $\mathrm{CO}_{2}$ retention syndromes and early ARDS.

\section{Material and methods}

All animals received humane care according to "Guide for the Care and Use of Laboratory Animals" (1985) prepared by the U.S. Department of Health and Human Services and published by the National Institutes of Health. The study was approved by the Institutional Animal Care and Use Committee of the University of Texas Medical Branch, Galveston, Tex., and performed with strict adherence to Committee guidelines regarding humane use of animals.

Adult Suffolk ewes ( $n=6,33 \pm 5 \mathrm{~kg}$ ) were used to investigate the effect of prolonged ( 7 days) $\mathrm{AVCO}_{2} \mathrm{R}$ in a smoke inhalation injury model of severe respiratory failure. Femoral and pulmonary arterial lines were placed in the animals three days before the experiment. Baseline hemodynamic variables including heart rate, cardiac output, mean arterial pressure, pulmonary artery pressure, central venous pressure, and pulmonary artery wedge pressure were measured immediately before injury. After endotracheal intubation, anesthesia was maintained with inhaled halothane delivered through a volume-controlled ventilator (Servo 900C, Siemens-Elema). Tracheostomy was performed followed by cotton severe smoke inhalation/insufflation to induce severe respiratory failure to a median lethal dose as previously described. ${ }^{18}$ Animals were then allowed to recover from anesthesia and the lungs mechanically ventilated. Initial postinjury ventilator settings were as follows: respiratory rate 25 to 30 breaths/ min, tidal volume $15 \mathrm{ml} / \mathrm{kg}$, fraction of inspired oxygen $\left(\mathrm{FiO}_{2}\right) 1.0$, and positive end-expiratory pressure $5 \mathrm{~cm} \mathrm{H}_{2} \mathrm{O}$. $\mathrm{FiO}_{2}$ was reduced once the carboxyhemoglobin level was less than $10 \%$ and maintained at a level sufficient to provide an arterial oxygen tension $\left(\mathrm{PaO}_{2}\right)$ level greater than $60 \mathrm{~mm} \mathrm{Hg}$. Hemodynamic variables and ventilator settings including minute ventilation and peak inspiratory pressure (PIP) were recorded. Arterial and mixed venous blood gas values were also measured every 6 hours, with minute ventilation and $\mathrm{FiO}_{2}$ adjusted to maintain arterial $\mathrm{pH}$ at 7.35 to $7.45, \mathrm{PaO}_{2}$ at 60 to $150 \mathrm{~mm} \mathrm{Hg}$, and arterial carbon dioxide tension $\left(\mathrm{PaCO}_{2}\right)$ at 30 to $40 \mathrm{~mm} \mathrm{Hg}$.

After 24 hours of volume-controlled ventilation, the sheep were reanesthetized and underwent systemic anticoagulation (300 IU/kg bovine lung heparin, Upjohn, Kalamazoo, Mich.) and cannulation of the left carotid artery (18F TF018LH, Research Medical, Midvale, Utah) and the left jugular vein (22F TF022L, Research Medical). A membrane gas exchanger (Affinity, Avecor Cardiovascular, Plymouth, Minn.) was primed with normal saline solution $(270 \mathrm{ml})$ and connected to the vascular cannulas after de-airing. Animals were then allowed to recover from anesthesia and have free access to food and water. Activated clotting time (Hemochron 400, Interna- 


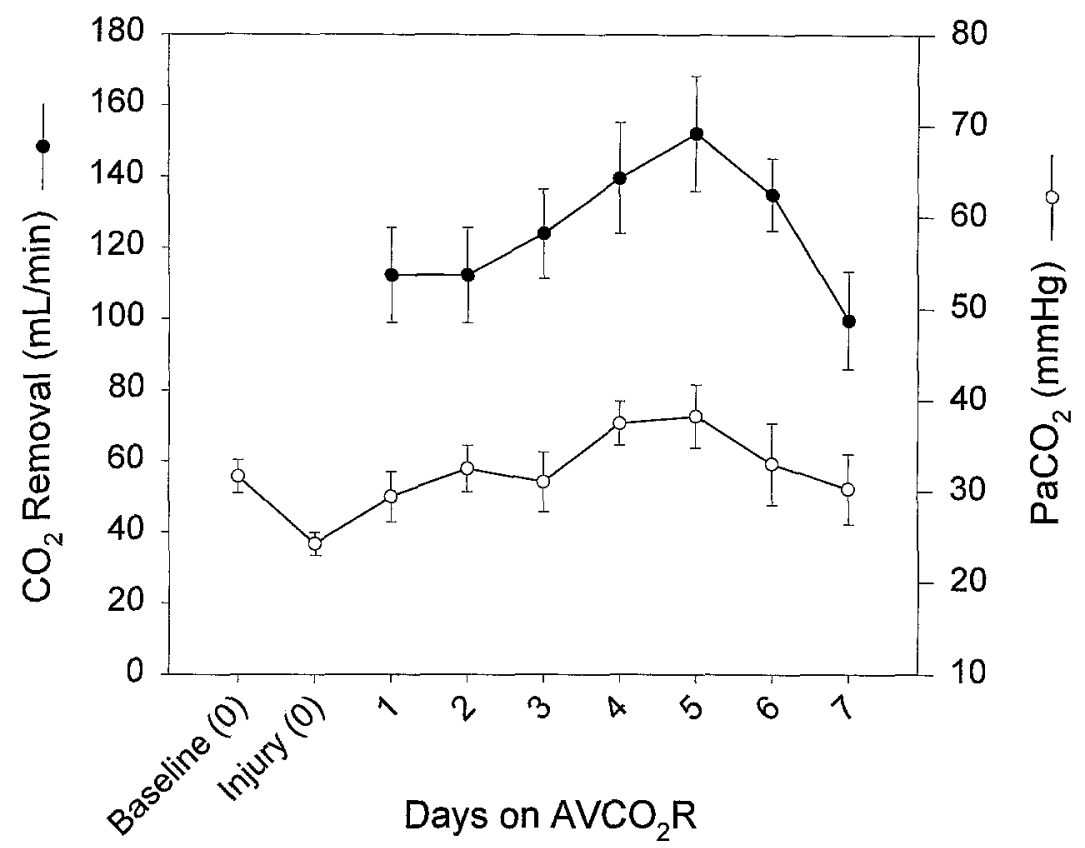

Fig. 1. $\mathrm{CO}_{2}$ removal during 7 days of $\mathrm{AVCO}_{2} \mathrm{R}$ in an ovine model of severe smoke inhalation injury peaks at day 5 and begins a slow downward trend as the animal recovers and resumes more efficient gas exchange via the native lungs. Values of $\mathrm{PaCO}_{2}$ (scaled on the right ordinate) remained within the normal range throughout the study. Values given as mean plus or minus the standard deviation. Baseline, Day 0, before injury; injury, day 0 , before $\mathrm{AVCO}_{2} \mathrm{R}$.

tional Technidyne, Edison, N.J.) was maintained between 300 and $500 \mathrm{sec}$ with a continuous heparin infusion throughout the study. The animals were then allowed to recover and continued to receive ventilator support before initiation of $\mathrm{AVCO}_{2} \mathrm{R}$.

On the initiation of $\mathrm{AVCO}_{2} \mathrm{R}$ flow with extracorporeal $\mathrm{CO}_{2}$ removal, ventilator support was reduced in a stepwise fashion as previously described. ${ }^{17}$ Initial reductions were made in tidal volume to reduce the PIP to less than $30 \mathrm{~cm}$ $\mathrm{H}_{2} \mathrm{O}$. Once targeted airway pressures were achieved, the respiratory rate was incrementally reduced to allow greater spontaneous respirations. Concurrently, the $\mathrm{FiO}_{2}$ was reduced as the $\mathrm{PaO}_{2}$ value remained above a threshold of $60 \mathrm{~mm} \mathrm{Hg}$. Positive end-expiratory pressure ranged from 5 to $10 \mathrm{~cm} \mathrm{H} \mathrm{H}_{2} \mathrm{O}$. With full $\mathrm{AVCO}_{2} \mathrm{R}$ flow, ventilator reductions continued daily throughout the study period until repeated blood gas sampling demonstrated $\mathrm{PaO}_{2}$ values greater than $60 \mathrm{~mm} \mathrm{Hg}$ with an $\mathrm{FiO}_{2}$ of 0.21 and systemic $\mathrm{PaCO}_{2}$ values remained less than $40 \mathrm{~mm} \mathrm{Hg}$, at which point mechanical ventilation was discontinued. Daily measurements of heart rate, cardiac output, mean arterial pressure, pulmonary artery pressure, blood flow, PIP, and $\mathrm{CO}_{2}$ removal were recorded and systemic and pulmonary vascular resistance values were calculated and compared with baseline measurements.

$\mathrm{AVCO}_{2} \mathrm{R}$ blood flow was monitored by an ultrasonic flow probe (model H6X, Transonic Systems, Ithaca, N.Y.) placed on the arterial cannula and interfaced with a real-time flowmeter (model HT 109, Transonic Systems) with a digital display. The arteriovenous pressure gradient across the gas exchanger was calculated on the basis of the difference between the inlet and outlet pressures. Sweep gas flow (100\% oxygen) was controlled by an in-line regulator. $\mathrm{CO}_{2}$ removal by the device was calculated as the product of sweep gas flow and its exhaust $\mathrm{CO}_{2}$ concentration measured by an in-line capnometer (SaraTrans, Lenexa, Kans.). The animals received 24-hour bedside care and continued to receive mechanical ventilation for 7 days or until successfully weaned from ventilator support.

Data are expressed as mean plus or minus the standard error of the mean and were displayed and analyzed by the SigmaPlot and SigmaStat programs (Jandel Scientific, San Rafael, Calif.). Comparisons with baseline values (before injury) were made by one-way analysis of variance with Dunnett's test, with time treated as repeated measures.

\section{Results}

All animals survived the study period with five $(83 \%)$ of six weaned from the ventilator before day 7. $\mathrm{AVCO}_{2} \mathrm{R}$ allowed a reduction in ventilator pressure settings to maintain PIP at less than $30 \mathrm{~cm} \mathrm{H}_{2} \mathrm{O}$ throughout the study. $\mathrm{CO}_{2}$ removal via $\mathrm{AVCO}_{2} \mathrm{R}$ ranged from $99.7 \pm 13.7$ to $152.2 \pm 16.2 \mathrm{ml} / \mathrm{min}$ over the course of the 7 days, while maintaining normocapnia $\left(\mathrm{PaCO}_{2} \leq 40 \mathrm{~mm} \mathrm{Hg}\right.$ ) (Fig. 1). Peak $\mathrm{CO}_{2}$ removal occurred at day 5 corresponding to the 

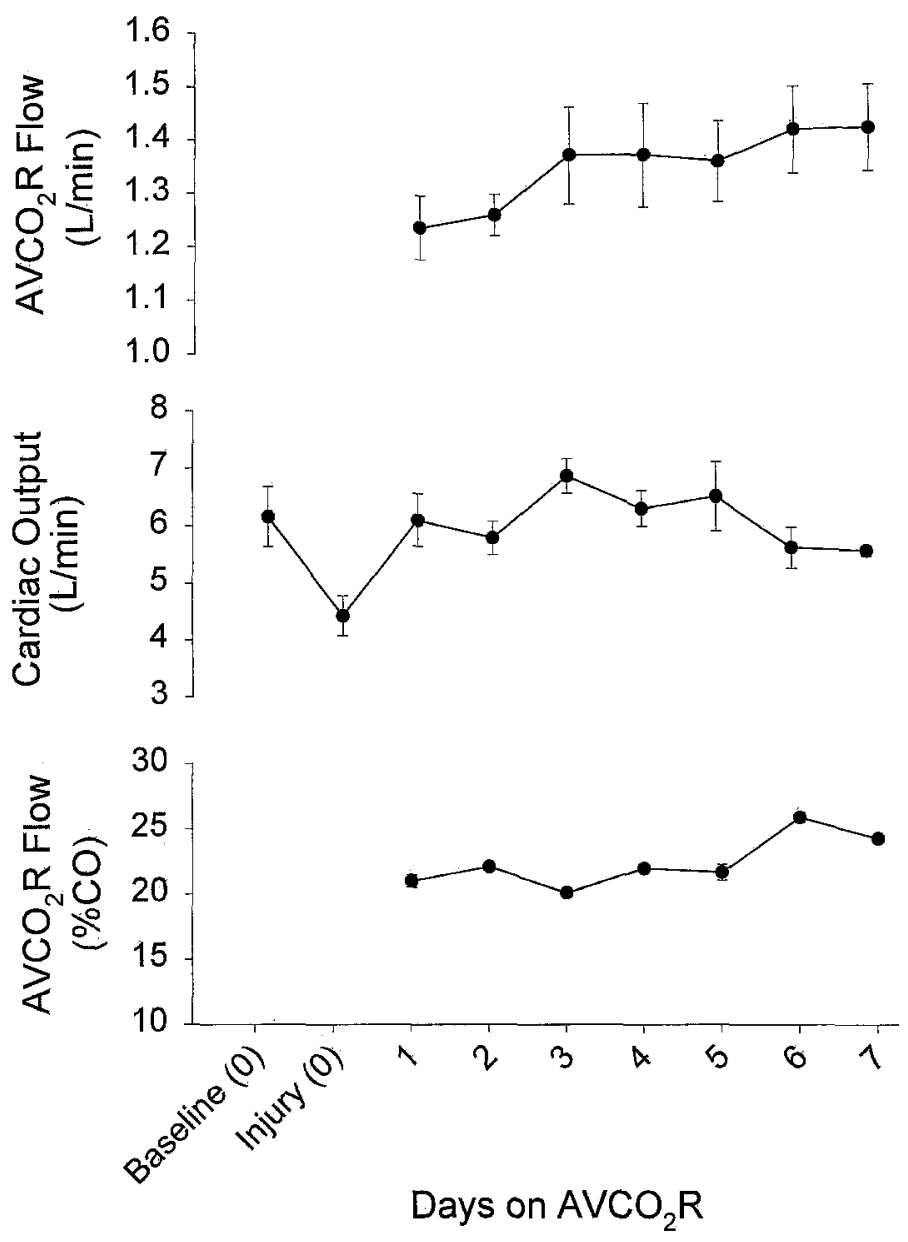

Fig. 2. $\mathrm{AVCO}_{2} \mathrm{R}$ blood flow and cardiac output remained stable and $\mathrm{AVCO}_{2} \mathrm{R}$ flow ranged from $20.1 \%$ $\pm 1.4 \%$ to $25.9 \% \pm 2.4 \%$ cardiac output for 7 days. Values given as mean plus or minus the standard deviation. Baseline, Day 0, before injury; injury, day 0 , before $\mathrm{AVCO}_{2} \mathrm{R}$.

anticipated full manifestation of the severe smoke inhalation injury. After day 5, as the animals' lungs recovered and native lung ventilation increased, $\mathrm{AVCO}_{2} \mathrm{R}$ blood flow was decreased in a stepwise fashion and extracorporeal $\mathrm{CO}_{2}$ removal subsequently decreased. The values for extracorporeal flow rate, cardiac output, and flow as a percentage of cardiac output can be seen in Fig. 2. $\mathrm{AVCO}_{2} \mathrm{R}$ flow throughout the 7-day study period ranged from $1.24 \pm 0.06$ to $1.43 \pm 0.08 \mathrm{~L} / \mathrm{min}$, accounting for $20.1 \% \pm 1.4 \%$ to $25.9 \% \pm 2.4 \%$ of the cardiac output. Heart rate, mean arterial pressure, and pulmonary artery pressure values remained relatively constant and were not statistically different as compared with baseline values at any time during the study (Fig. 3). Likewise there were no significant changes in systemic or pulmonary vascular resis- tance associated with $\mathrm{AVCO}_{2} \mathrm{R}$ (Fig. 4). The pressure gradient across the oxygenator was less than 10 $\mathrm{mm} \mathrm{Hg}$, and there were no changes in the inlet and outlet pressures throughout the 7-day study. No clots were observed in the $\mathrm{AVCO}_{2} \mathrm{R}$ circuit at necropsy. There were no observed incidences of acute or episodic hemodynamic instability or hemorrhagic or thromboembolic events throughout the 7-day study. Despite the severity of the injury and significant reduction in ventilatory support, $\mathrm{PaO}_{2}$ was maintained at greater than $75 \mathrm{~mm} \mathrm{Hg}$ with an $\mathrm{FiO}_{2}$ of less than 0.5 at all times.

\section{Discussion}

Our recent work has shown that $\mathrm{AVCO}_{2} \mathrm{R}$ is a simple technique to achieve total $\mathrm{CO}_{2}$ removal in a large animal model of ARDS in which flow up to 


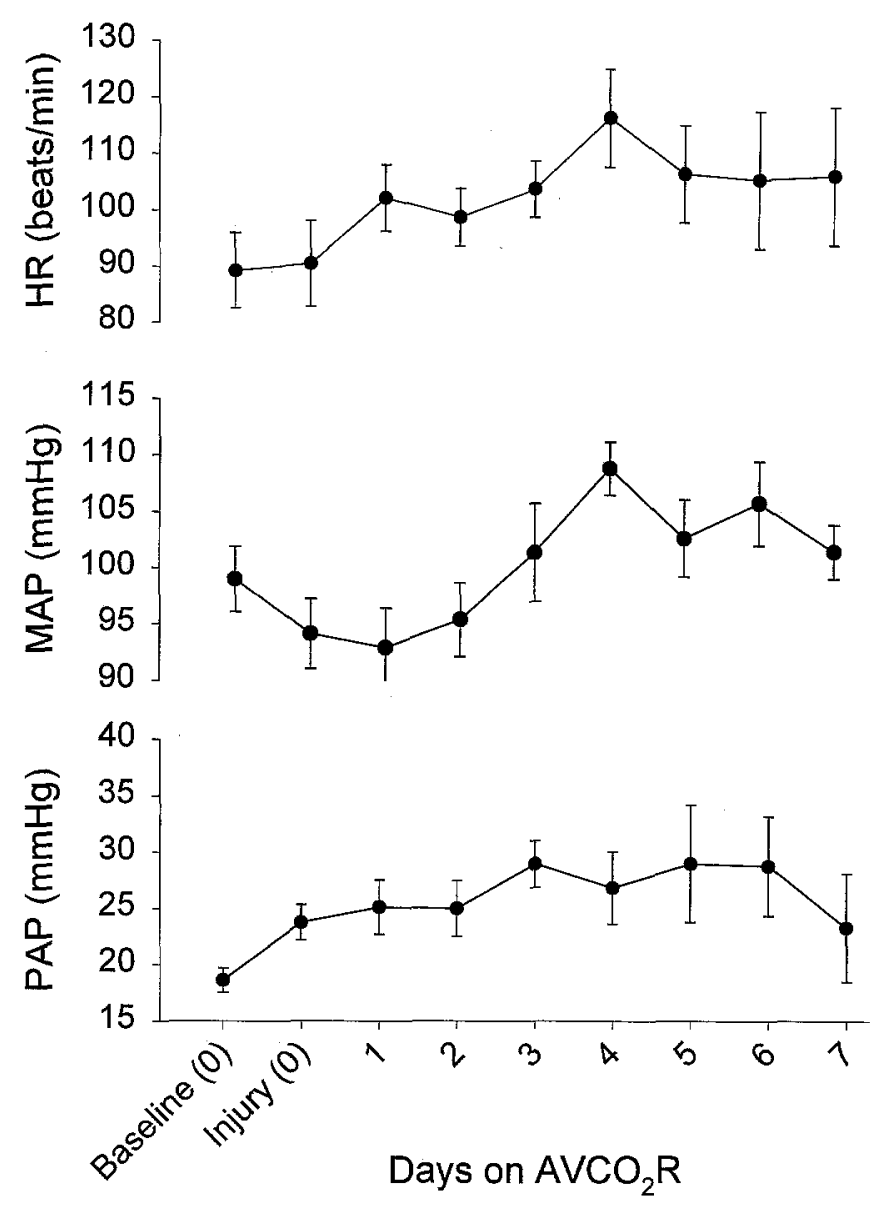

Fig. 3. Heart rate $(H R)$, mean arterial pressure $(M A P)$, and pulmonary artery pressure $(P A P)$ during the 7-day period of $\mathrm{AVCO}_{2} \mathrm{R}$ revealed no statistically significant differences at any time. Values given as mean plus or minus the standard deviation. Baseline, Day 0 , before injury; injury, day 0, before $\mathrm{AVCO}_{2} \mathrm{R}$.

$29 \%$ cardiac output achieved total $\mathrm{CO}_{2}$ removal and significantly reduced minute ventilation and peak airway pressures. ${ }^{17}$ In our initial studies of the performance characteristics of $\mathrm{AVCO}_{2} \mathrm{R}$, we determined that the quantity of $\mathrm{CO}_{2}$ removed is directly dependent on blood flow through the gas exchanger. ${ }^{16}$ In healthy sheep, $\mathrm{AVCO}_{2} \mathrm{R}$ flow of $0.5 \mathrm{~L} / \mathrm{min}$ removes a sufficient quantity of $\mathrm{CO}_{2}$ to maintain normocapnia, and mild permissive hypercapnia $\left(\mathrm{PaCO}_{2}\right.$ of 60 to $70 \mathrm{~mm} \mathrm{Hg}$ ) results when $\mathrm{AVCO}_{2} \mathrm{R}$ flow is reduced to only $0.2 \mathrm{~L} / \mathrm{min}^{19}{ }^{19}$ Sufficient flow to achieve total $\mathrm{CO}_{2}$ removal with $\mathrm{AVCO}_{2} \mathrm{R}$ allows a significant reduction in ventilator airway pressure requirements and attendant barotrauma/volutrauma to the native lung alveoli. Before pediatric and adult clinical application of $\mathrm{AVCO}_{2} \mathrm{R}$ for $\mathrm{CO}_{2}$ retention syndromes or early ARDS, prolonged use of $\mathrm{AVCO}_{2} \mathrm{R}$ must be demonstrated to be tolerated hemodynamically without significant changes in heart rate, cardiac output, mean arterial pressure, pulmonary artery pressure, blood flow, PIP, or $\mathrm{CO}_{2}$ removal. Therefore this study in a large animal model of ARDS was necessary to provide a risk/benefit assessment for the initial phase I clinical trials.

Patients with ARDS are often in a hemodynamically unstable condition with a tendency toward either a hypodynamic ${ }^{20}$ or a hyperdynamic ${ }^{21}$ state depending on the cause and progression of ARDS. Volume- or pressure-controlled mechanical ventilation inflicts positive intrapleural pressure and may exacerbate such instability by directly affecting venous return and pulmonary vascular resistance. Modified ventilator management strategies, such as varying levels of positive end-expiratory pressure ${ }^{22}$ and manipulation of the inspiration/expiration ratio, ${ }^{23}$ have also been shown to change hemodynam- 

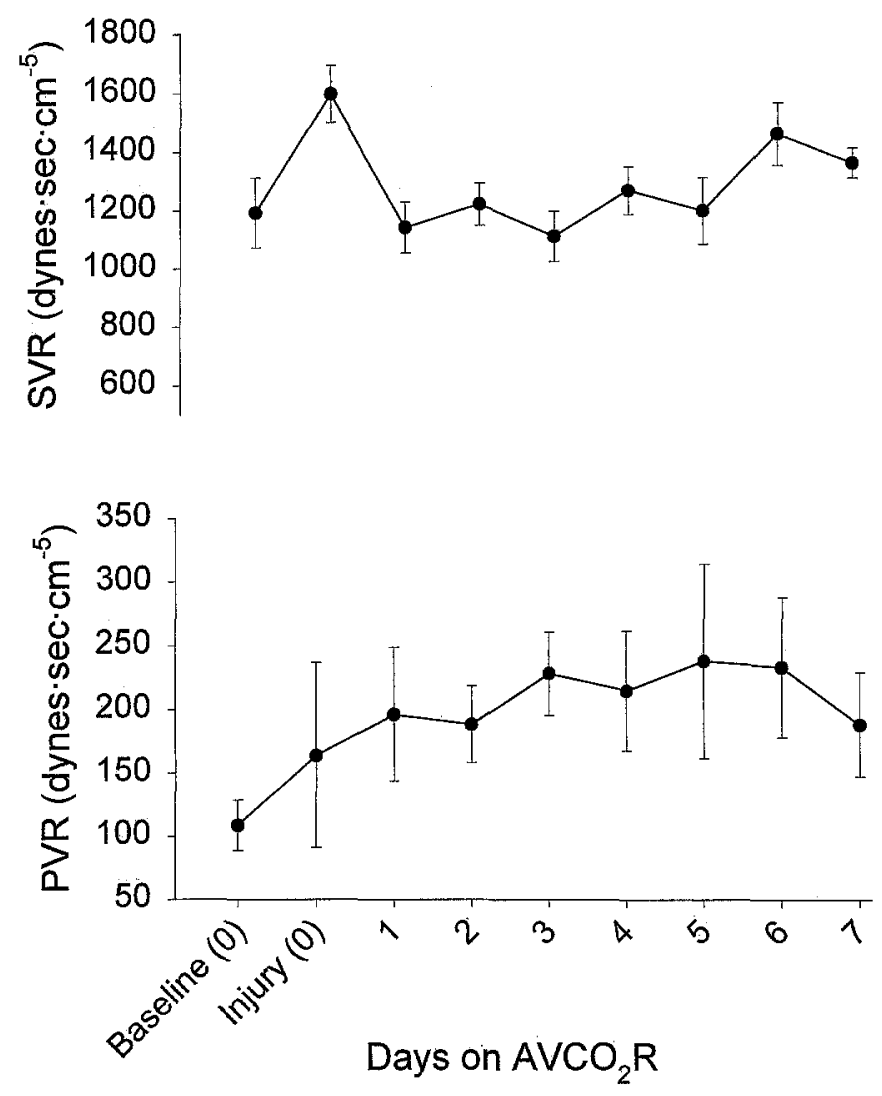

Fig. 4. Systemic vascular resistance $(S V R)$ and pulmonary vascular resistance (PVR) calculated from directly measured variables during the 7-day period of $\mathrm{AVCO}_{2} \mathrm{R}$ revealed no statistically significant difference at any time. Values given as mean plus or minus the standard deviation. Baseline, Day 0 , before injury; injury, day 0 , before $\mathrm{AVCO}_{2} \mathrm{R}$.

ics or organ blood flow during ARDS in both animal models and human beings. Permissive hypercapnia leads to increases in cardiac output, organ blood flow, and intracerebral pressure, ${ }^{24}$ but these effects can be attenuated by the administration of sodium bicarbonate to offset the respiratory acidosis. The overall disease process and the resultant treatment are potentially additive in their impact on hemodynamic stability. The application of an additional treatment modality, that is, $\mathrm{AVCO}_{2} \mathrm{R}$, which uses up to $20 \%$ to $30 \%$ of the cardiac output to alleviate the need for excessive ventilator therapy to remove $\mathrm{CO}_{2}$, could result in cardiac decompensation and worsening of the condition. On the other hand, by allowing $\mathrm{CO}_{2}$ removal to occur without the need for continued ventilation with potentially harmful levels of volume and pressure, $\mathrm{AVCO}_{2} \mathrm{R}$ allows a reduction in the applied airway pressures and resultant intrathoracic pressures and minimizes the hemodynamic insult caused by impairment of venous return and cardiac output. These factors are paramount when considering $\mathrm{AVCO}_{2} \mathrm{R}$ for use and must be fully understood before a treatment is initiated that may predispose an already critically ill patient to further hemodynamic compromise.

Early investigations into the physiologic response to an arteriovenous shunt in normal dogs showed that shunt flows ranging from $17 \%$ to $130 \%$ of the baseline cardiac output revealed either no change or a decrease of 10 to $30 \mathrm{~mm} \mathrm{Hg}$ in mean arterial pressure. $^{25}$ Frank and coworkers ${ }^{26}$ showed that a reflex vasoconstrictor response prevented a fall in mean arterial pressure and that physiologic accommodation occurred up to a shunt equal to or greater than $60 \%$ of the baseline cardiac output. These studies relied on extensive instrumentation in anesthetized, healthy animals and may not accurately reflect the true adaptive response. A long-term (2-month) rat model of an aortocaval fistula, totaling $50 \%$ of the cardiac output, demonstrated that 
physiologic adaptation resulted in high-output cardiac failure with ventricular hypertrophy and regional blood flow redistribution. ${ }^{27}$ This study illustrated the adaptation to an unusually large shunt in the rat, but a more clinically relevant short-term study with significantly lower shunt flows is necessary for $\mathrm{AVCO}_{2} \mathrm{R}$.

Several examples of arteriovenous shunts used for specific patient care circumstances or large animal studies exist. Gentilello and colleagues ${ }^{28-30}$ applied a simple percutaneous arteriovenous shunt connected to a countercurrent heat exchanger to speed rewarming in animals and patients with clinically significant hypothermia and reported a spontaneous arteriovenous shunt flow rate of 225 to $375 \mathrm{ml} / \mathrm{min}$ did not significantly alter hemodynamics. This method was significantly more efficient than simple external rewarming and was tolerated without adverse events or the need for anticoagulation. Awad and colleagues ${ }^{14}$ showed that $\mathrm{AVCO}_{2} \mathrm{R}$ support for up to 7 days could be tolerated without adverse hemodynamic sequelae in healthy dogs and sheep. More recently studies in a canine model of acute oleic acid injury with an oxygenator in a pumpless arteriovenous shunt with flow rates sufficient to achieve adequate gas exchange (25\% of baseline cardiac output) resulted in decreases in mean arterial pressure and systemic vascular resistance that could be attenuated with a dopamine infusion. ${ }^{15}$ These studies were done in an anesthetized animal with an oleic acid model known to be associated with hemodynamic compromise. ${ }^{31,32}$

Our data confirmed that despite a $20 \%$ to $26 \%$ cardiac shunt through the $\mathrm{AVCO}_{2} \mathrm{R}$ circuit for 7 days, there was no instability in the hemodynamic profile, specifically in heart rate, cardiac output, mean arterial pressure, pulmonary artery pressure, or $\mathrm{AVCO}_{2} \mathrm{R}$ flow. These data suggest that, in addition to its use in healthy animals, ${ }^{14,33}$ long-term, high-flow $\mathrm{AVCO}_{2} \mathrm{R}$ can be tolerated by adult sheep with severe respiratory failure without sequelae. The extremely low circuit resistance $(<10 \mathrm{~mm} \mathrm{Hg})$ allows the $\mathrm{AVCO}_{2} \mathrm{R}$ circuit to appear as an insignificant component of the overall systemic resistance without hemodynamic compromise on initiation of $\mathrm{AVCO}_{2} \mathrm{R}$ flow. Redistribution of blood flow, with decreased blood flow to muscles and skin and sustained blood flow to the brain and heart, has been observed in the high-shunt, high-output cardiac failure model in conscious rats. ${ }^{27}$ Some elements of this adaptive physiologic state may have been present during our 7-day study. In addition, increased intrathoracic pressure as a result of positive-pressure ventilation will reduce venous return and subsequently cardiac output and systemic arterial blood pressure. By achieving a significant reduction in ventilatory pressures and eliminating hypercapnia, $\mathrm{AVCO}_{2} \mathrm{R}$ may have attenuated changes in hemodynamics that would have otherwise been manifested during the study as a result of increased intrathoracic pressure from mechanical ventilation.

In our study, oxygenation was maintained with an $\mathrm{FiO}_{2}$ ranging from 0.21 to 0.50 , which was sufficient to maintain systemic $\mathrm{PaO}_{2}$ values at greater than 75 $\mathrm{mm} \mathrm{Hg}$ throughout the 7 days. $\mathrm{AVCO}_{2} \mathrm{R}$ is not useful to provide supplemental $\mathrm{O}_{2}$ delivery when the arterial $\mathrm{PaO}_{2}$ level is adequate because the inflow to the gas exchanger is already well saturated, with $\mathrm{O}_{2}$ carrying capacity at a maximum. To illustrate, hemoglobin is assumed to be $10 \mathrm{gm} / \mathrm{dl}$, inlet $\mathrm{O}_{2}$ saturation is $90 \%$ (corresponding to a $\mathrm{PaO}_{2}$ value of $60 \mathrm{~mm} \mathrm{Hg}$ ), outlet $\mathrm{O}_{2}$ saturation is $100 \%$, and $\mathrm{AVCO}_{2} \mathrm{R}$ flow is $1.4 \mathrm{~L} / \mathrm{min}$. The $\mathrm{AVCO}_{2} \mathrm{R} \mathrm{O}$ exchange capacity under these conditions is at a theoretic maximum of approximately $19 \mathrm{ml} / \mathrm{min}$. Estimating $\mathrm{O}_{2}$ consumption at 150 to $250 \mathrm{ml} / \mathrm{min}$ per square meter, $\mathrm{AVCO}_{2} \mathrm{R}$ contributes little to the overall oxygenation in a patient, especially in a patient who is in a hypermetabolic condition with an increased $\mathrm{O}_{2}$ demand related to the disease state. If the alveoli are maintained open with the application of positive end-expiratory pressure, the passive diffusion of constant-flow $\mathrm{O}_{2}$ across the alveolar membrane is adequate for systemic oxygenation as demonstrated by the technique of apneic oxygenation first popularized by Kolobow. ${ }^{10}$ There is also a small benefit related to the increased $\mathrm{O}_{2}$ content of the mixed venous blood reaching the pulmonary precapillary bed, which results in a slight alteration in the normal vasoconstrictive response to local hypoxia with a resultant reduction in pulmonary shunt.

In conclusion, $\mathrm{AVCO}_{2} \mathrm{R}$ can be used for total $\mathrm{CO}_{2}$ removal for up to 7 days in an adult sheep model of severe respiratory failure without hemodynamic compromise or instability. The blood flow rates necessary to achieve total $\mathrm{CO}_{2}$ removal by $\mathrm{AVCO}_{2} \mathrm{R}$ to provide lung rest may allow vascular access with percutaneous cannulas. Our goal is to provide a simple bedside management tool to augment gas exchange in cases of developing ARDS to allow decreased barotrauma/volutrauma at an early stage when favorable outcomes are likely. In addition, the relative hemodynamic stability of this animal model of ARDS during prolonged $\mathrm{AVCO}_{2} \mathrm{R}$ 
validates the safety of this technique for clinical trials to evaluate $\mathrm{AVCO}_{2} \mathrm{R}$ in syndromes of $\mathrm{CO}_{2}$ retention and early respiratory failure in the adult and, subsequently, pediatric populations.

\section{REFERENCES}

1. Demling RH. The modern version of adult respiratory distress syndrome. Annu Rev Med 1995;46:193-202.

2. Suchyta MR, Clemmer TP, Elliott CG, Orme JF Jr, Weaver LK. The adult respiratory distress syndrome: a report of survival and modifying factors. Chest 1992;101:1074-9.

3. Tsuno K, Prato P, Kolobow T. Acute lung injury from mechanical ventilation at moderately high airway pressures. J Appl Physiol 1990;69:956-61.

4. Tsuno K, Miura K, Takeya M, Kolobow T, Morioka T. Histopathologic pulmonary changes from mechanical ventilation at high peak airway pressures. Am Rev Respir Dis 1991;143:1115-20.

5. Parker JC, Hernandez LA, Peevy KJ. Mechanisms of ventilator-induced lung injury. Crit Care Med 1993;21:131-43.

6. Hickling KG, Walsh J, Henderson S, Jackson R. Low mortality rate in adult respiratory disease syndrome using lowvolume, pressure-limited ventilation with permissive hypercapnia: a prospective study. Crit Care Med 1994;22:1568-78.

7. Ichiba S, Bartlett RH. Current status of extracorporeal membrane oxygenation for severe respiratory failure. Artif Organs 1996;20:120-3.

8. Gattinoni $\mathrm{L}$, Kolobow $\mathrm{T}$, Tomlinson $\mathrm{T}$, et al. Low-frequency positive pressure ventilation with extracorporeal carbon dioxide removal (LFPPV-ECCO 2 R): an experimental study. Anesth Analg 1978;57:470-7.

9. Gattinoni L, Pesenti A, Mascheroni D, et al. Low-frequency positive-pressure ventilation with extracorporeal $\mathrm{CO}_{2}$ removal in severe acute respiratory failure. JAMA 1986;256: 881-6.

10. Kolobow T, Gattinoni L, Tomlinson T, Pierce JE. An alternative to breathing. J Thorac Cardiovasc Surg 1978;75:261-6.

11. Zwischenberger JB, Nguyen TT, Upp JR Jr, et al. Complications of neonatal extracorporeal membrane oxygenation: collective experience from the Extracorporeal Life Support Organization. J Thorac Cardiovasc Surg 1994;107:838-49.

12. Mortensen JD. An intravenacaval blood gas exchange (IVCBGE) device: a preliminary report. ASAIO Trans 1987; 33:570-3.

13. Barthelemy R, Galletti PM, Trudell LA, et al. Total extracorporeal $\mathrm{CO}_{2}$ removal in a pumpless artery-to-vein shunt. Trans Am Soc Artif Intern Organs 1982;28:354-8.

14. Awad JA, Deslauriers J, Major D, Guojin L, Martin L. Prolonged pumpless arteriovenous perfusion for carbon dioxide extraction. Ann Thorac Surg 1991;51:534-40.

15. Chapman J, Adams M, Geha AS. Hemodynamic response to pumpless extracorporeal membrane oxygenation. J Thorac Cardiovasc Surg 1990;99:741-50.

16. Brunston RL Jr, Tao W, Bidani A, Cardenas VJ Jr, Traber DL, Zwischenberger JB. Determination of low blood flow limits for arteriovenous carbon dioxide removal $\left(\mathrm{AVCO}_{2} \mathrm{R}\right)$. ASAIO J 1996;M42:845-51.

17. Tao W, Brunston RL Jr, Bidani A, et al. Significant reduction in minute ventilation and peak inspiratory pressures with arteriovenous carbon dioxide removal during severe respiratory failure. Crit Care Med 1997;25:689-95.
18. Kimura R, Traber LD, Herndon DN, Linares HA, Lubbesmeyer HJ, Traber DL. Increasing duration of smoke exposure induces more severe lung injury in sheep. J App! Physiol 1988;64:1107-13.

19. Brunston RL Jr, Zwischenberger JB, Tao W, Cardenas VJ Jr, Traber DL, Bidani A. Total arteriovenous carbon dioxide removal $\left(\mathrm{AVCO}_{2} \mathrm{R}\right)$ : simplifying extracorporeal support for severe respiratory failure. Ann Thorac Surg. In press.

20. Meade P, Shoemaker WC, Donnelly TJ, et al. Temporal patterns of hemodynamics, oxygen transport, cytokine activity, and complement activity in the development of adult respiratory distress syndrome after severe injury. J Trauma 1994;36:651-7.

21. Ronco JJ, Belzberg A, Phang PT, Walley KR, Dodek PM, Russell JA. No differences in hemodynamics, ventricular function, and oxygen delivery in septic and nonseptic patients with the adult respiratory distress syndrome. Crit Care Med 1994;22:777-82.

22. Hickling KG. Ventilatory management of ARDS: can it affect the outcome? Intensive Care Med 1990;16:219-26.

23. Lessard MR, Guerot E, Lorino H, Lemaire F, Brochard L. Effects of pressure-controlled with different I:E ratios versus volume-controlled ventilation on respiratory mechanics, gas exchange, and hemodynamics in patients with adult respiratory distress syndrome. Anesthesiology 1994;80:983-91.

24. Cardenas VJ Jr, Zwischenberger JB, Tao W, et al. Correction of blood $\mathrm{pH}$ attenuates changes in hemodynamics and organ blood flow during permissive hypercapnia. Crit Care Med 1996;24:827-34.

25. Wegria R, Nakano J, McGiff JC, Rochester DF, Blumenthal MR, Murkin JM. Effect of arteriovenous fistula on mean arterial blood pressure, coronary blood flow, cardiac output, oxygen consumption, work and efficiency. Am J Physiol 1958; $193: 147-50$.

26. Frank CW, Wang HH, Lammerant J, Miller R, Wegria R. An experimental study of the immediate hemodynamic adjustments to acute arteriovenous fistulae of various sizes. J Clin Invest 1955;34:722-31.

27. Flaim SF, Minteer WJ, Nellis SH, Clark DP. Chronic arteriovenous shunt: evaluation of a model for heart failure in rat. Am J Physiol 1979;236:H697-704.

28. Gentilello LM, Cobean RA, Offner PH, Soderberg RW, Jurkovich GJ. Continuous arteriovenous rewarming: rapid reversal of hypothermia in critically ill patients. J Trauma 1992;32:316-27.

29. Gentilello LM, Rifley WJ. Continuous arteriovenous rewarming: report of a new technique for treating hypothermia. J Trauma 1991;31:1151-4.

30. Gentilello LM, Cortes V, Moujaes S, et al. Continuous arteriovenous rewarming: experimental results and thermodynamic model simulation of treatment for hypothermia. J Trauma 1990;30:1436-49.

31. Dodek PM, Valenzuela A, Minshall DK, Baile EM, Pare PD. Bronchial vascular occlusion does not attenuate or accentuate oleic acid lung injury in anesthetized sheep. J Appl Physiol 1993;75:2671-6.

32. Chiang CH, Shen CY, Hsu K. Correlation between cardiopulmonary changes and severity of acute lung injury in dogs. Crit Care Med 1990;18:419-22.

33. Young JD, Dorrington KL, Blake GJ, Ryder WA. Femoral arteriovenous extracorporeal carbon dioxide elimination using low blood flow. Crit Care Med 1992;20:805-9. 